\title{
Magnitude of Stunting and Associated Factors Among 6-59 Months Old Children in Hossana Town, Southern Ethiopia
}

Beminet Moges $^{1}$, Amsalu Feleke ${ }^{2}$, Solomon Meseret ${ }^{3}$ and Feleke Doyore ${ }^{1^{*}}$

${ }^{1}$ Lecturer and Researchers, Department of Public Health, Faculty of Medicine and Health Sciences, Wachemo University, Ethiopia

${ }^{2}$ Associate professor and Researchers, Institute of Public Health, College of Health Sciences, University of Gondar, Ethiopia

${ }^{3}$ Assistant professor and Researchers, Institute of Public Health, College of Health Sciences, University of Gondar, Ethiopia

*Corresponding author: Feleke Doyore, Department of Public Health, Faculty of Medicine and Health Sciences, Wachemo University, Ethiopia, Tel: 251932685424; Email: feledoag@yahoo.com

Rec date: Dec 01, 2014, Acc date: Jan 20, 2015, Pub date: Jan 25, 2015

Copyright: (C) 2015 Moges B, et al. This is an open-access article distributed under the terms of the Creative Commons Attribution License, which permits unrestricted use, distribution, and reproduction in any medium, provided the original author and source are credited.

\begin{abstract}
Introduction: Stunting remains a public health problem of greater magnitude and it more accurately reflects nutritional deficiencies of the most critical periods of growth and development in early life. Therefore, the study was aimed to assess the magnitude of stunting and associated factors among 6-59 months old children in Hosanna town, Southern Ethiopia.
\end{abstract}

Methods: A community based cross-sectional study was conducted using a simple random sampling technique with a sample size of 734 children, aged 6-59 months. The structured questionnaires were used to collect data. Data analysis was done by SPSS version 20 and ENA for SMART, 2011 software.

Results: The study result reveals that $35.4 \%$ of 6-59 months old children were stunted, with even higher rates among male children $138(53.1 \%)$. Children more likely to be stunted included: those between 24 and 35 months $(A O R=2.29 ; 95 \% \mathrm{Cl}: 1.10,4.82)$, those whose mothers had no education ( $\mathrm{AOR}=5.38 ; 95 \% \mathrm{Cl}: 2.27,12.77)$, those from a low income household (AOR=3.92; $95 \% \mathrm{Cl}: 2.54,6.06)$, those who were physically small at birth (AOR=2.10; $95 \% \mathrm{Cl}: 1.13,3.93$ ), having birth order of 4 and above (AOR=2.32; $95 \% \mathrm{Cl}: 1.28,4.21$ ), those who breastfed for longer than 24 months $(\mathrm{AOR}=2.49 ; 95 \% \mathrm{Cl}: 1.03,6.00)$, and those whose mothers did not use a cup to feed their children $(\mathrm{AOR}=2.08 ; 95 \% \mathrm{Cl}: 1.05,4.15)$.

Conclusion: The findings of this study have proven stunting were a high prevalent problem in the study area. The child's age, mother's education level, household income, birth order, size at birth, duration of breastfeeding and cup feeding were found to be associated factors of stunting. All of the factors, except birth order, could be reversed through thoughtful programming. The findings of this study suggest that there is potential need for linking nutrition interventions in the study area.

Keywords: Child stunting; 6-59 Months children; Malnutrition; Ethiopia

\section{Introduction}

Malnutrition is an underlying cause of more than 2.6 million child deaths every year, a third of the total of child deaths. Every hour of every day, 300 children die because of malnutrition but it's not recorded on death certificates and, as a result, it's not effectively addressed $[1,2]$.

Worldwide, an estimated 171 million children are stunted because of poor nutrition in the earliest months of life. More than a third of children in Asia are stunted, which accounts for almost 100 million of the global total. In Africa, almost two in five children are stunted that is a total of 60 million children [2,3].

Stunting is defined by a Height-for-Age (HAZ) Z-score below two SDs of the median WHO standards [4]. The first 1,000 days of life beginning with conception, through a mother's pregnancy and up until the age of two is the most critical period in a child's development [3].
Stunting is an indicator of chronic malnutrition, meaning longterm or accumulated nutritional deficiency resulting from lack of adequate dietary intake over a long period of time and/or recurrent illness. Stunting is caused by inadequate diet and by infection as immediate level. These primary causes of malnutrition are influenced by food access and availability, healthcare, water and sanitation, and the way a child is cared for such as whether the infant is breastfed and whether basic hygiene practices are used which includes hand-washing $[3,5,6]$.

Stunting in early childhood also results in diminished cognitive and physical development, which puts children at a disadvantage for the rest of their lives. They may perform poorly in school, and as adults they may be less productive, earn less and face a higher risk of disease than adults who were not undernourished as children $[6,7]$.

Height at two years of age is clearly associated with enhanced productivity and human capital in adulthood, so early nutrition is also an important contributor to economic development in which a $1 \%$ loss in adult height due to childhood stunting is associated with a $1.4 \%$ loss in productivity [5]. Progress in reducing childhood malnutrition in 
developing countries has been slow. The larger burden for Africa is stunting that is the failure to grow in stature [8].

Stunting is continued to be one of the most important public health problems in Ethiopia. In urban Ethiopia based on 2011 EDHS the prevalence of stunting in under five children was $32 \%$ which is with $2.2 \%$ increase in five years from 2005 EDHS $[9,10]$.

Therefore, this study is aimed to assess the magnitude of stunting and associated factors among under five children in Hossana town, Southern Ethiopia. Furthermore, the findings of this study will enable policy makers, public health advocators, nutritionists and researchers used as baseline data to design appropriate and effective interventions.

\section{Subjects and Methods}

\section{Study area and period}

This study was conducted in Hossana town. Hosanna is located 230 $\mathrm{km}$ south west from the capital city of Ethiopia being the capital city of Hadiya zone. The study period was as of March 15 to April 15, 2013.

\section{Study design and populations}

Community based cross sectional study design was used to assess the magnitude of stunting and associated factors among 6-59 months old children in Hossana town. All sampled respondents of the Hossana town from the randomly selected kebele who were present during study period were included.

\section{Sample size and sampling procedures}

The sample size was calculated using single population proportion formula by considering $32 \%$ of estimated proportion of under five children were stunted in Ethiopia, margin of error 5\%, a 5\% level of significance (two sided) i.e. 95\% confidence interval of certainty. Based on the above assumptions, with an additional 10 percent contingency for non-response, the final sample size was 334. Considering the design effect of 2 and with an additional 10 percent contingency for non-response; the total sample size was 734. Simple random sampling technique was used to select study participants from each kebele.

\section{Measurement and variables}

\section{Dependent variable: Stunting (Height-for-age)}

Independent variables: Socio-demographic factors, Environmental factors, Health care factors and Dietary factors.

Socio economic and demographic factors: Age, ethnicity, religion, marital status of the mother, mother's education, father's education, mother's occupation, father's occupation, household monthly income, birth order, preceding birth interval. Environmental factors: Source of drinking water and latrine facility availability. Health care factors: child's weight and size at birth, child immunization status, child morbidity, mother's antenatal care visits, mother's age at pregnancy, mother's place of delivery. Dietary factors: ever breast feeding, time for initiation of breast feeding, colostrums feeding, pre-lacteal feeding, duration of breastfeeding, age for introduction of complementary food method of feeding. Stunting means children whose height-for-age $\mathrm{Z}$ score is below minus two standard deviations (-2 SD) from the median of the WHO reference population are considered short for their age (stunted). Recurrent episodes of diarrhea is to mean child who have 2 or more an episode of diarrhea begins with a 24 -hour period with three or more loose or watery stools and an episode of diarrhea is considered to have ended after 48 hours without three or more loose or watery stools within a 24-hour period Which Is determined as perceived by mother. Fully vaccinated is to mean children who have received vaccination against tuberculosis (BCG), three doses each of the DPT and polio vaccines, and a measles vaccination by the age of 12 months. Currently on vaccination with age mean children who have receiving a vaccination according to the schedule because of their age. Non-Fully vaccinated is to mean children who have not received three doses each of the DPT, a vaccination against tuberculosis (BCG), and polio vaccines, and a measles vaccination by the age of 12 months according to the standard immunization schedule. Size at birth means based on mothers' estimation and verbal report. Pre-lacteal feeding is to mean children given something other than breast milk during the first three days of life. Duration of breastfeeding means the number of months of breastfeeding among children. Complementary feeding means the child receives both breast milk or a breast milk substitute and solid (semi-solid or soft) foods. Low income is to mean households with monthly income below mean income of the sample $1,745 \mathrm{ETB}$. High income is to mean households with monthly income $1,745 \mathrm{ETB}$ and above the mean income of the sampled households.

\section{Data collection instrument and procedure}

Data on stunting and demographic, socio-economic, environmental healthcare and dietary factors among children age (6-59 months) was collected using structured questionnaire. The questionnaire was adapted from different literatures of similar studies in English to increase the comparability of the finding. Anthropometry measurements mainly height for age was used. For height, length measurement for children below 24 months was taken in laying down or recumbent position and standing height was taken for children 24-59 months and the measurement was taken to the nearest $0.1 \mathrm{~cm}$ using UNICEF standard Height Measuring Board with the subjects shoeless [11,12], and for age, the child's age was collected from the mother and confirmed by using birth certificate or vaccination cards and also we were used a "local-events calendar" $[11,12]$.

\section{Data quality management, processing and analysis}

Questionnaires were translated to local language and then back translated to English to maintain its consistency. Training was given for data collectors and pretest was done on $5 \%$ of the study subjects on similar population out of study area. Supervisors and principal investigator performed immediate supervision on a daily basis. The collected data were entered in SPSS 20.0 version for analysis. Anthropometric measurement data was entered and analyzed by Emergency Nutrition Assessment (ENA) for SMART 2011 software. Descriptive analysis was used to describe the percentages and number of distributions of the respondents by socio-demographic factors, environmental factors, health care factors and dietary factors. Furthermore, bivariate and multivariable logistic regression analyses were used to identify the influencing factors using backward variable selection techniques. All explanatory variables that were associated with outcome variable in bivariate analysis with p-value of 0.25 or less were included in the initial logistic models. The Crude Odds Ratio (COR) and Adjusted Odds Ratios (AOR) together with their corresponding $95 \%$ confidence intervals were computed and interpreted accordingly. A P-value $<0.05$ was considered to declare a result as statistically significant in this study. 
Citation: $\quad$ Moges B, Feleke A, Meseret S, Doyore F (2015) Magnitude of Stunting and Associated Factors Among 6-59 Months Old Children in

Page 3 of 8

\section{Ethical consideration}

Ethical clearance was obtained from the Institute of Public Health, University of Gondar Ethical committee. Prior to data collection, a formal letter was obtained from University of Gonder and submitted to each kebele. The purposes and importance of the study was explained and written informed consent was secured from each mother of the children. Confidentiality was maintained at all levels of the study.

All study participants was informed that participation in this research project have no incentives or direct benefit. Participant's involvement in the study was on voluntary basis. Participants who are unwilling to participate in the study and those who wish to quit their participation at any stage were informed to do so without any restriction.

\section{Results}

\section{Demographic and socio-economic characteristics}

A total of 734 children aged 6-59 months were included in analysis with response rate $100 \%$. Of the 734 under-five children in the study, $374(51 \%)$ were female and, $234(31.9 \%)$ found in the age group 12-24 months. The mean age of the participants was $26.72 \pm 13.07$ months (Table 1).

\begin{tabular}{|c|c|c|c|}
\hline \multicolumn{2}{|l|}{ Variables } & \multirow{2}{*}{$\begin{array}{l}\text { Frequency } \\
360\end{array}$} & \multirow{2}{*}{$\begin{array}{l}\text { Percent } \\
49.0\end{array}$} \\
\hline Sex of Child & Male & & \\
\hline & Female & 374 & 51.0 \\
\hline \multirow[t]{5}{*}{ Children's age in month } & $6-11$ & 91 & 12.4 \\
\hline & $12-23$ & 234 & 31.9 \\
\hline & $24-35$ & 200 & 27.2 \\
\hline & $36-47$ & 137 & 18.7 \\
\hline & $48-59$ & 72 & 9.8 \\
\hline \multirow{3}{*}{$\begin{array}{l}\text { Mother's age at } \\
\text { Pregnancy }\end{array}$} & Less than 20years & 49 & 6.7 \\
\hline & 20 to 35 years & 672 & 91.6 \\
\hline & More than 35years & 13 & 1.8 \\
\hline \multirow{4}{*}{$\begin{array}{l}\text { Marital status of the } \\
\text { mother }\end{array}$} & Married & 682 & 92.9 \\
\hline & Divorced & 34 & 4.6 \\
\hline & Widowed & 15 & 2.0 \\
\hline & Never married & 3 & .4 \\
\hline \multirow[t]{6}{*}{ Ethnicity } & Hadiya & 471 & 64.2 \\
\hline & Kembata & 113 & 15.4 \\
\hline & Silte & 58 & 7.9 \\
\hline & Guraghe & 49 & 6.7 \\
\hline & Amhara & 27 & 3.7 \\
\hline & Oromo & 16 & 2.2 \\
\hline Religion & Protestant & 504 & 68.7 \\
\hline
\end{tabular}

\begin{tabular}{|c|c|c|c|}
\hline & Orthodox & 117 & 15.9 \\
\hline & Muslim & 84 & 11.4 \\
\hline & Catholic & 29 & 4.0 \\
\hline \multirow[t]{4}{*}{ Mother's education } & No education & 86 & 11.7 \\
\hline & Primary & 258 & 35.1 \\
\hline & Secondary & 268 & 36.5 \\
\hline & More than secondary & 122 & 16.6 \\
\hline \multirow[t]{4}{*}{ Father's education } & No education & 45 & 6.1 \\
\hline & Primary & 186 & 25.3 \\
\hline & Secondary & 292 & 39.8 \\
\hline & More than secondary & 211 & 28.7 \\
\hline \multirow[t]{5}{*}{ Mother's occupation } & House wife & 406 & 55.3 \\
\hline & Government employee & 83 & 11.3 \\
\hline & $\begin{array}{l}\text { Non-Government } \\
\text { employee }\end{array}$ & 29 & 4.0 \\
\hline & Merchant & 122 & 16.6 \\
\hline & Self-employee & 280 & 38.1 \\
\hline \multirow[t]{4}{*}{ Father's occupation } & Government employee & 223 & 30.4 \\
\hline & $\begin{array}{l}\text { Non-Government } \\
\text { employee }\end{array}$ & 49 & 6.7 \\
\hline & Merchant & 182 & 24.8 \\
\hline & Self-employee & 280 & 38.1 \\
\hline \multirow{2}{*}{$\begin{array}{l}\text { Household monthly } \\
\text { income in ETB }\end{array}$} & Low income House hold & 409 & 55.7 \\
\hline & High income House hold & 325 & 44.3 \\
\hline
\end{tabular}

Table 1: Demographic and socio-economic characteristics of children among 6 to 59 months in Hossana town, Southern Ethiopia, 2013 $(\mathrm{n}=734)$.

\section{Health care and environmental characteristics}

$547(74.5 \%)$ of children participated in the study were normal size and $132(18.0 \%)$ were small size at birth according to the mother verbal reports. From the children, majority, 728(99.2\%) received vaccination and 686(94.2\%) children were fully immunized (Table 2).

\section{Dietary characteristics}

Breast feeding was almost universal in the study area children who breast fed were 723(98.5\%). 523(71.3\%) children started breast feeding within the first one hour (Table 3 ).

\section{Magnitude of stunting among 6-59 months children}

In the analysis stunting was defined as having a $\mathrm{z}$ score below $-2 \mathrm{SD}$ of the WHO standards. The prevalence of stunting among children of 6-59 months in the study area was $35.4 \%$ (34.6-36.3; 95\%:C.I.). The prevalence was $79(30.4 \%)$ in children age group 12-23 months. Of the total $138(53.1 \%)$ of male children were stunted. 
Citation: $\quad$ Moges B, Feleke A, Meseret S, Doyore F (2015) Magnitude of Stunting and Associated Factors Among 6-59 Months Old Children in Hossana Town, Southern Ethiopia. J Clinic Res Bioeth 6: 207. doi:10.4172/2155-9627.1000207

Page 4 of 8

\begin{tabular}{|c|c|c|c|}
\hline \multicolumn{2}{|l|}{ Variables } & \multirow{2}{*}{$\begin{array}{l}\text { Frequency } \\
34\end{array}$} & \multirow{2}{*}{\begin{tabular}{|l|}
$\%$ \\
4.6
\end{tabular}} \\
\hline \multirow{4}{*}{ ANC visits of mother } & None & & \\
\hline & 1 & 18 & 2.5 \\
\hline & $2-3$ & 292 & 39.8 \\
\hline & 4 and above & 390 & 53.1 \\
\hline \multirow[t]{3}{*}{ Mother's age at Pregnancy } & Less than 20years & 49 & 6.7 \\
\hline & 20 to 35 years & 672 & 91.6 \\
\hline & More than 35years & 13 & 1.8 \\
\hline \multirow[t]{3}{*}{ Mothers place of delivery } & Public facility & 563 & 76.7 \\
\hline & Private facility & 27 & 3.7 \\
\hline & Home & 144 & 19.6 \\
\hline \multirow[t]{2}{*}{ PNC attendance of Mother } & Yes & 83 & 11.3 \\
\hline & No & 651 & 88.7 \\
\hline \multirow[t]{3}{*}{ Birth order } & 1 & 351 & 47.8 \\
\hline & $2-3$ & 286 & 39.0 \\
\hline & 4 and above & 97 & 13.2 \\
\hline \multirow[t]{2}{*}{ Preceding birth interval( $n=383)$} & Less than 24 months & 160 & 41.8 \\
\hline & More than 24 months & 223 & 58.2 \\
\hline \multirow[t]{3}{*}{ Child's size at birth } & Small & 168 & 22.9 \\
\hline & Normal & 477 & 65.0 \\
\hline & Large & 89 & 12.1 \\
\hline \multirow[t]{3}{*}{ Immunization Status } & Fully immunized & 686 & 94.2 \\
\hline & $\begin{array}{l}\text { Currently } \\
\text { immunization }\end{array}$ & 36 & 4.9 \\
\hline & Not fully immunized & 6 & .8 \\
\hline \multirow[t]{2}{*}{ Diarrhea in the past 2 weeks } & Yes & 122 & 16.6 \\
\hline & No & 612 & 83.4 \\
\hline \multirow{2}{*}{$\begin{array}{l}\text { Had recurrent diarrhea in the } \\
\text { past } 2 \text { weeks }\end{array}$} & Yes & 36 & 4.9 \\
\hline & No & 698 & 95.1 \\
\hline \multirow[t]{3}{*}{ Main source of drinking water } & Piped into dwelling & 363 & 49.5 \\
\hline & Piped to yard/plot & 274 & 37.3 \\
\hline & Public tap /Stand pipe & 97 & 13.2 \\
\hline \multirow[t]{2}{*}{ Toilet facility availability } & Yes & 717 & 97.7 \\
\hline & No & 17 & 2.3 \\
\hline
\end{tabular}

\begin{tabular}{|c|c|c|c|}
\hline \multicolumn{2}{|l|}{ Variables } & \multirow{2}{*}{$\begin{array}{l}\text { Frequency } \\
723\end{array}$} & \multirow{2}{*}{$\begin{array}{l}\% \\
98.5\end{array}$} \\
\hline Ever breast fed child & Yes & & \\
\hline & No & 11 & 1.5 \\
\hline \multirow{3}{*}{$\begin{array}{l}\text { Time for initiation of Breast } \\
\text { Feeding }(n=723)\end{array}$} & Within 1 hour & 523 & 71.3 \\
\hline & Within 24 hours & 194 & 26.4 \\
\hline & More than 24 hours & 6 & .8 \\
\hline \multirow{2}{*}{$\begin{array}{l}\text { Child received pre-lacteal } \\
\text { feeds }(n=723)\end{array}$} & Yes & 137 & 18.9 \\
\hline & No & 586 & 81.1 \\
\hline \multirow[t]{2}{*}{ Child fed colostrums $(n=723)$} & Yes & 644 & 89.1 \\
\hline & No & 79 & 10.9 \\
\hline \multirow{3}{*}{$\begin{array}{l}\text { Duration of breastfeeding } \\
(n=723)\end{array}$} & Less than 12 months & 171 & 23.7 \\
\hline & 12 - 24 months & 474 & 65.6 \\
\hline & More than 24 months & 78 & 10.8 \\
\hline \multirow{2}{*}{$\begin{array}{l}\text { Age complementary food } \\
\text { started }\end{array}$} & At 6 months & 501 & 68.3 \\
\hline & $\begin{array}{l}\text { Before and after } \\
\text { 6months }\end{array}$ & 233 & 31.7 \\
\hline \multirow[t]{2}{*}{ Cup for feeding } & Yes & 260 & 35.4 \\
\hline & No & 474 & 64.6 \\
\hline \multirow[t]{2}{*}{ Spoon for feeding } & Yes & 697 & 95.0 \\
\hline & No & 37 & 5.0 \\
\hline \multirow[t]{2}{*}{ Hand for feeding } & Yes & 548 & 74.7 \\
\hline & No & 186 & 25.3 \\
\hline \multirow[t]{2}{*}{ Bottle for feeding } & Yes & 364 & 49.6 \\
\hline & No & 370 & 50.4 \\
\hline
\end{tabular}

Table 3: Dietary characteristics of children among 6 to 59 Months in Hossana town, Southern Ethiopia, 2013 ( $n=734)$.

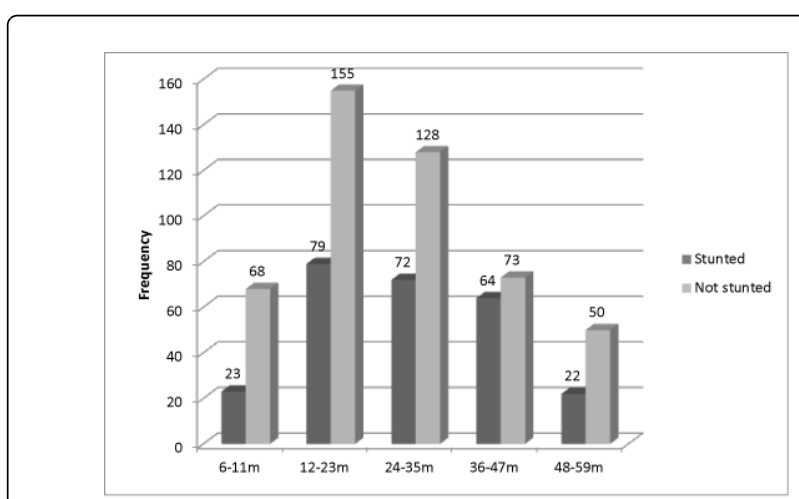

Table 2: Health care and environmental characteristics of children among 6 to 59 months in Hossana town, Southern Ethiopia, 2013 $(\mathrm{n}=734)$.

Figure 1: Prevalence of stunting with age groups among children 6-59 months in Hossana town, Southern Ethiopia, 2013. 
Citation: $\quad$ Moges B, Feleke A, Meseret S, Doyore F (2015) Magnitude of Stunting and Associated Factors Among 6-59 Months Old Children in Hossana Town, Southern Ethiopia. J Clinic Res Bioeth 6: 207. doi:10.4172/2155-9627.1000207

Page 5 of 8

\begin{tabular}{|c|c|c|c|c|c|}
\hline \multirow[t]{2}{*}{ Explanatory Variables } & \multicolumn{2}{|c|}{ Stunting } & \multirow[t]{2}{*}{ COR $95 \% \mathrm{Cl}$} & \multirow[t]{2}{*}{ AOR $95 \% \mathrm{Cl}$} & \multirow[t]{2}{*}{ P-Value } \\
\hline & Yes & No & & & \\
\hline \multicolumn{6}{|l|}{ Children's age in month } \\
\hline $6-11$ & 23 & 68 & 1 & 1 & \\
\hline $12-23$ & 79 & 155 & $1.51(0.87,2.59)$ & $2.47(0 \quad .85,7.21)$ & 0.098 \\
\hline $24-35$ & 72 & 128 & $1.66(0.96,2.89)$ & $2.29(1.10,4.82)$ & 0.029 \\
\hline $36-47$ & 64 & 73 & $2.59(1.45,4.63)$ & $2.29(1.10,4.76)$ & 0.027 \\
\hline $48-59$ & 22 & 50 & $1.30(0.65,2.59)$ & $3.34(1.58,7.06)$ & 0.002 \\
\hline \multicolumn{6}{|l|}{ Mothers Education } \\
\hline No education & 50 & 24 & $13.24(6.53,26.81)$ & $5.38(2.27,12.77)$ & $<0.001$ \\
\hline Primary & 122 & 143 & $5.42(3.08,9.54)$ & $1.69(0.85,3.40)$ & 0.137 \\
\hline Secondary & 71 & 199 & $2.27(1.27,4.04)$ & $1.388(0.70,2.76)$ & 0.350 \\
\hline Above secondary & 17 & 108 & 1 & 1 & \\
\hline \multicolumn{6}{|l|}{ Monthly income in ETB } \\
\hline Less than 1745 & 206 & 203 & $5.09(3.59,7.23)$ & $3.92(2.54,6.06)$ & $<0.001$ \\
\hline 1745 and more & 54 & 271 & 1 & 1 & \\
\hline \multicolumn{6}{|l|}{ Birth order } \\
\hline First & 104 & 247 & 1 & 1 & \\
\hline $2-3$ & 110 & 176 & $1.48(1.07,2.07)$ & $1.35(0.88,2.05)$ & 0.17 \\
\hline 4 and above & 46 & 51 & $2.14(1.35,3.39)$ & $2.32(1.28,4.21)$ & 0.006 \\
\hline \multicolumn{6}{|l|}{ Child's size at birth } \\
\hline Small & 114 & 54 & $2.59(1.53,4.39)$ & $2.10(1.13,3.93)$ & 0.020 \\
\hline Normal & 106 & 371 & $0.35(0.22,0.56)$ & $0.30(0.17,0.53)$ & $<0.001$ \\
\hline Larger & 40 & 49 & 1 & 1 & \\
\hline \multicolumn{6}{|c|}{ Duration of Breast Feeding } \\
\hline Less than 12 months & 46 & 135 & 1 & 1 & \\
\hline 12 - 24 months & 172 & 301 & $1.77(1.19,2.62)$ & $2.35(1.18,4.66)$ & 0.015 \\
\hline More than 24 months & 42 & 38 & $3.40(1.94,5.99)$ & $2.49(1.03,6.00)$ & 0.042 \\
\hline \multicolumn{6}{|l|}{ Cup for feeding } \\
\hline Yes & 218 & 42 & 1 & 1 & \\
\hline No & 454 & 20 & $4.37(2.51,7.63)$ & $2.08(1.05,4.15)$ & 0.037 \\
\hline
\end{tabular}

Table 4: Factors associated with prevalence of stunting among children 6-59 months in Hossana town, Southern Ethiopia 2013 ( $\mathrm{n}=734$ ).

\section{Factors associated with stunting among 6-59 months children}

In the study sex of child, father education, mother occupation and father occupation, ANC visits of mother, preceding birth interval and immunization status of the child, household main source of drinking water and also child received pre-lacteal feeds, child feed colostrums, age complementary food started, hand feeding and bottle feeding were significantly associated with stunting in bivariate analysis but the association disappears in the multivariate logistic regression analysis. 
The finding of the study indicated that, Child's age, mother's education, monthly income, and size at birth, birth order, duration of breast feeding, and cup feeding were identified as determinants of stunting among children in the study area in the multivariate logistic regression analysis.

Child's age was one of the risk factors which significantly associated with stunting in the study area. Comparing with children 6-11 months, children within age group 24-35 months were 2.29 times more likely to develop stunting (AOR=2.29; 95\%CI:1.10, 4.82). and children within age group 36-47 months were 2.29 times more likely to develop stunting than children age 6-11months (AOR=2.29; 95\%CI: $1.10,4.76)$. The result also indicated that, children within age group 48-59 months were 3.34 times more likely to develop stunting than children age 6-11 months (AOR=3.34; 95\%CI:1.58, 7.06).

From the analysis, children whose mothers had no education were 5.4 times more likely to be stunted as compared to mother with educational status of above secondary (AOR=5.38; 95\%CI:2.27, 12.77). Children from household with low monthly income were 3.92 times more likely to be stunted than children from high monthly income (AOR=3.92; 95\%CI: 2.54, 6.06).

Children who had born with small size were 2.10 times more likely to be stunted than children born larger $(\mathrm{AOR}=2.10$; $95 \% \mathrm{CI}$ : 1.13 , 3.93). The result also showed that children who had normal birth size were $70 \%$ less likely to develop stunting as compared to children with large birth size (AOR=0.30; 95\%CI:0.17, 0.53).

The result of the study indicated that, birth order of the child was associated with risk of stunting. Children of 4 and above birth order were 2.3 times more likely to be stunted than children of first birth order $(\mathrm{AOR}=2.32$; 95\% CI: 1.28, 4.21).

Duration of breast feeding was associated with risk of stunting in the study. Children who had been breast feed for 12-23 months long were 2.35 times more likely to be stunted than children who breast feed for than less than 12 months long (AOR=2.35; 95\%CI:1.18, 4.66). In the study finding children who had breast feed for more than 24 months long were 2.49 times more likely to be stunted than children who breast feed for than less than 12 months long ( $\mathrm{AOR}=2.49$; 95\%CI: $1.03,6.00)$.

Cup feeding as method of feeding was also associated with risk of stunting in the study. In the study mothers not used cup to feed their children were 2.08 times more likely to be stunted than mothers used cup to feed their children (AOR=2.08; 95\%CI:1.05, 4.15) (Table 4).

\section{Discussion}

This study tried to assess the prevalence of stunting and associated factors among 6-59 months children. Based on the findings, the prevalence of stunting in this study was 35.4\% (34.6-36.3 95\% C.I).This study was in line with study conducted in Ghana, 36\% [13]. The magnitude of stunting in this study was higher than study conducted in Peru 26.6\% [14], Brazil 29.9\% [15], Sirlanka 11.8\% [16], South Africa 20.2\% [17] and Egypt 13.8\% [18] and the national prevalence in EDHS 2006, 29.8\% [10] and EDHS done in 2011,32\% [9]. However, the prevalence of stunting in the study was lower than study conducted in, Nepal 37\% [19], India 51.6\% [20], Lao PDR 40\% [21], Cambodia 38.6\% [22] also the study conducted in Democratic Republic of Congo 43.9\% [23] ,Uganda 41.6\% [24], Tanzania 44\% [25], Kenya 40\% [26], Sudan Khartoum 51\% [27] and Ethiopia 42\% [28]. This difference might be due to population migration from rural to urban in order to get better job and living condition, decreased purchasing power of the community, increment of food prices, inappropriate infant and young child feeding practices and child health care.

Child's age was one of the factors significantly associated with stunting in the study area. Comparing with children 6-11 months, children within age group 24-35 months, 36-47 months and 48-59 months were more likely to be stunted. The finding was in agreement with the study in Ethiopia [28] and Egypt [18]. This might be due to stunting in children age 24 months and above were resulted from poor nutritional status of mother's at pregnancy, inappropriate infant and young child feeding practices and other related factors which were needed to be undergone beginning from conception, through a mother's pregnancy and up until the age of two which was the most critical period in a child's development after child reaches above 24 months of age stunting was irreversible.

Mother's education was another variable which significantly associated with stunting. Children whose mothers had no education were more likely to be stunted as compared to mother with educational status of above secondary. This finding was consistent to the study conducted in India [20], Tanzania [25], and Nairobi Kenya [26] and also in Ethiopia $[9,28,29]$. This might be due to mother who had no education had shortage of knowledge which related to better child feeding and caring, low income and low living conditions.

Birth order of children is one of the demographic variables explaining the risk of stunting in children. Children of 4 and above birth order were more likely to be stunted than children of first birth order. This finding was in line with the study conducted In Cambodia [22], Nairobi Kenya [26], and Egypt [18]. This might be due to family unable to satisfy child dietary and other health care related services because of more number of children and might also be due to low awareness of family planning.

Children from household with low monthly income were more likely to be stunted than children from high monthly income households. This might be children from low income households had low access to adequate dietary intake in kinds and the amounts and also it may be due to increment of food prices, decreased purchasing power of the family and also shortage of other important materials and utilities.

Children who had born with small size were more likely develop stunting than children born larger. The finding was in line with the study conducted In Kenya [26].This may be due to the mother's health and nutritional status before and during pregnancy in which determined size of the child during intra-uterine period and also those small sized children were frequently exposed to an infection which leads to mal absorption of nutrients in their body.

The result of the study also indicated that children who had normal birth size were less likely to develop stunting as compared to children with large birth size. The finding of this study might be due to children having optimal birth weight was mostly protective to most disease conditions related to proper growth and maturity of their body may help them to sustain the external environment.

Duration of breast feeding was associated with risk of stunting in the study. Children who had been breast feed for 12-23 months long and more than 24 months long were more likely to be stunted than children who breast feed for than less than 12 months long. The association between continued breast-feeding and stunting was also 
observed in similar studies conducted in Cambodia [18], Disha et al. in Zambia and Ethiopia [30] and also study conducted in Gojam North west Ethiopia [29]. This might be due to poor maternal nutrition status which mothers who are breastfeeding need two additional meals a day and had direct relation with breast milk quality and quantity, even if the duration of breast feeding long poorly attached and positioned breast feeding could affect the optimal breast feeding of children and mothers of children continue breast feeding without providing adequate, safe, appropriate solid, semi-solid and soft foods for the children which directly related to children growth.

Cup feeding as method of feeding was also associated with risk of stunting in the study. In the study children whose mothers not used cup to feed them were more likely to be stunted than children whose mothers used cup to feed children. The studies which directly support this finding was not available at this point in time but WHO/UNICEF child feeding guideline support the use of cup as a method can prevent the contamination. This might be due to mothers low awareness about the advantages of cup feeding and mothers of children who were not used cup as method of feeding they may use bottle as alternative method which was not recommended at any age to feed the children which was high risk of infection. The possible limitation of the study is being a cross-sectional study may cause difficulty in identifying causeeffect relationship. And recall bias is the other fear of the researcher. In conclusion, the study revealed that stunting is high prevalent problem among children 6-59 months of age in Hossana town, Southern Ethiopia. Child's age, mother's education, household income, birth order, size at birth, duration of breast feeding and cup feeding were found to be associated factors of stunting among 6-59 months children in the study area.

At last, based on the above findings of the study, the following recommendations are forwarded:

\section{For Federal Ministry of health}

Need to expand programmes which links nutrition interventions and social protection to reach young children and pregnant or breastfeeding mothers in urban communities.

\section{For Hossana town Health office}

Need to plan nutrition interventions to effectively address the nutritional conditions with participation of stakeholders and community at large.

\section{For health extension workers}

Need to give nutrition education for the community about maternal and child nutrition to accelerate prevention of stunting by focusing the most critical periods of child development.

Need to actively involve and give training to the mothers and care givers of children with practical demonstration of how to prepare and give optimal foods for infant and young child.

\section{For researchers}

Need to conduct further studies to determine the predictors of stunting using different analytic and longitudinal studies.

\section{Competing interests}

The authors declared that they have no competing interests.

\section{Authors' contributions}

Beminet Moges wrote the proposal, participated in data collection, analyzed the data and drafted the paper. Amsalu Feleke and Solomon Meseret approved the proposal with some revisions, supervised in data collection and analysis, commented on the analysis and improved the first draft. Feleke Doyore and Beminet Moges revised subsequent drafts of the paper and Feleke Doyore prepared this manuscript.

\section{Acknowledgment}

Our earnest gratitude goes to research committee of University of Gonder for proper review and approval of this paper. We are very happy to be in a position to thank data collectors to bring us these valuable findings. Our gratitude thanks goes to each kebele to their contribution in providing us baseline information and coordinating at a time of data collection. We would also like to extend our gratitude to respondents for their patience to give these valuable responses. Our thanks also extended to USAID/Empowering New Generation to Improve Nutrition and Economic opportunity (ENGINE) for financial support. Lastly but not least special thanks for Beimnet's wife Betel Seid for unreserved help for the accomplishment of the research work.

\section{References}

1. UNICEF (2012) The state of world children: Children in an Urban World. New York: World United Nations Children's Fund.

2. $\mathrm{M}$ de Onis (2011) Prevalence and trends of stunting among pre-school children 1990-2020. Unit Public Health Nutrition 14: 1-7

3. Save the Children UK (2012) A life free from hunger: Tackling child malnutrition. London: Save the Children Fund UK.

4. UNICEF (2011) Programming Guide: Infant and Young Child Feeding. New York : United Nations Children's Fund (UNICEF).

5. United Nations Children's Fund (UNICEF) (2009) Tracking progress on child and maternal nutrition: A survival and development priority. New York: United Nations Children's Fund.

6. Black RE, Allen LH, Bhutta ZA, Caulfield LE, de Onis M, et al. (2008) Maternal and child undernutrition: global and regional exposures and health consequences. Lancet 371: 243-260.

7. World Bank (2010) Lesson from a review of interventions to reduce child malnutrition in developing countries: what can we learn from nutrition impact evaluations? Washington D.C. The World Bank.

8. Jessica Fanzo (2012) The Nutrition Challenge in Sub-Saharan Africa. Rome: United Nation Development Programme (UNDP).

9. (2012) Central Statistical Agency [Ethiopia] and ICF International. Ethiopia Demographic and Health Survey 2011. Addis Ababa, Ethiopia and Calverton, Maryland, USA: Central Statistical Agency and ICF International.

10. Central Statistical Agency [Ethiopia], ICF International (2006) Ethiopia Demographic and Health Survey. Addis Ababa, Ethiopia and Calverton, Maryland, USA: Central Statistical Agency and ICF International.

11. WHO (2010) Nutrition Landscape Information System (NLIS) country profile indicators: interpretation guide. World Health Organization.

12. WHO Multicenter Growth Reference Study Group (2009) WHO Child Growth Standards: Growth velocity based on weight, length and head circumference: Methods and development, Geneva: World Health Organization.

13. Van de Poel E, Hosseinpoor AR, Jehu-Appiah C, Vega J, Speybroeck N (2007) Malnutrition and the disproportional burden on the poor: the case of Ghana. Int J Equity Health 6: 21.

14. Casapía M, Joseph SA, Núñez C, Rahme E, Gyorkos TW (2007) Parasite and maternal risk factors for malnutrition in preschool-age children in Belen, Peru using the new WHO Child Growth Standards. Br J Nutr 98: 1259-1266. 
Citation: $\quad$ Moges B, Feleke A, Meseret S, Doyore F (2015) Magnitude of Stunting and Associated Factors Among 6-59 Months Old Children in Hossana Town, Southern Ethiopia. J Clinic Res Bioeth 6: 207. doi:10.4172/2155-9627.1000207

Page 8 of 8

15. Ferreira AA, Welch JR, Santos RV, Gugelmin SA, Coimbra CE Jr (2012) Nutritional status and growth of indigenous Xavante children, Centra Brazil. Nutr J 11: 3.

16. TDR Peiris, DGNG Wijesinghe (2010) Nutritional Status of under 5 Year-Old Children and its Relationship with Maternal Nutrition Knowledge in Weeraketiya DS division of Sri Lanka. Tropical Agricultural Research 21: 330 - 339.

17. Zere E, McIntyre D (2003) Inequities in under-five child malnutrition in South Africa. Int J Equity Health 2: 7.

18. Zottarelli LK, Sunil TS, Rajaram S (2007) Influence of parental and socioeconomic factors on stunting in children under 5 years in Egypt. East Mediterr Health J 13: 1330-1342.

19. Sapkota V (2009) Prevalence and Predictors of Underweight, Stunting and Wasting in Under-Five Children. J Nepal Health Res Counc 7: 120-126.

20. Kumar D, Goel NK, Mittal PC, Misra P (2006) Influence of infantfeeding practices on nutritional status of under-five children.

21. Kamiya Y (2011) Socioeconomic determinants of nutritional status of children in Lao PDR: effects of household and community factors. J Health Popul Nutr 29: 339-348.

22. Hong R, Mishra V (2006) Effect of wealth inequality on chronic undernutrition in Cambodian children. J Health Popul Nutr 24: 89-99.

23. Kandala NB, Madungu TP, Emina JB, Nzita KP, Cappuccio FP (2011) Malnutrition among children under the age of five in the Democratic
Republic of Congo (DRC): does geographic location matter? BMC Public Health 11: 261.

24. Turyashemererwa F (2009) Prevalence of early child hood malnutrition and influencing factors in peri urban areas of kabarole district, Western Uganda. African journal of food agriculture nutrition and development 9: 4 .

25. Happiness S (2010) Persistent child malnutrition in Tanzania: Risks associated with traditional complementary foods (A review). African Journal of Food Science 4: 679-692

26. Abuya BA, Ciera J, Kimani-Murage E (2012) Effect of mother's education on child's nutritional status in the slums of Nairobi. BMC Pediatr 12: 80.

27. Ali M (2010) The impact of feeding practices on prevalence of under nutrition among 6-59 months aged children in Khartoum. Sudanese journal of public health 5: 3 .

28. Girma W, Genebo T (2002) Determinants of Nutritional Status of Women and Children in Ethiopia. Calverton, Maryland, USA: ORC Macro.

29. Macro International Inc (2008) Nutrition of Young Children and Women, Ethiopia 2005. Calverton, Maryland, USA: Macro International Inc.

30. Disha A (2012) Infant and young child feeding (IYCF) practice in Ethiopia and Zambia and their association with child nutrition: Analysis of Demographic and Health survey data. African journal of food, agriculture, nutrition and development (AJFAND) 12: 2. 